\title{
Network Pharmacology-Based Prediction of Active Ingredients and Mechanisms of Tongxinluo Against Acute Myocardial Infarction
}

\section{Meng-Jin Hu}

Fuwai Hospital State Key Laboratory of Cardiovascular Disease

\section{Gui-Hao Chen}

Fuwai Hospital State Key Laboratory of Cardiovascular Disease

Yue-Jin Yang ( $\nabla$ yangyj1266@163.com )

Fuwai Hospital State Key Laboratory of Cardiovascular Disease

\section{Original Research}

Keywords: Tongxinluo, myocardial infarction, network pharmacology, beta-sitosterol, oxidative stress

Posted Date: July 9th, 2021

DOI: https://doi.org/10.21203/rs.3.rs-673133/v1

License: (c) (i) This work is licensed under a Creative Commons Attribution 4.0 International License. Read Full License 


\section{Abstract}

Purpose: The aim of this network pharmacology was to explore the potential active ingredients and mechanisms of Tongxinluo (TXL) against acute myocardial infarction (AMI).

Methods: We selected active ingredients and targets of TXL according to TCMSP database and converted protein targets into gene symbol by UniProt database. Therapeutic gene targets on AMI were collected from DisGeNET and GeneCards databases. The overlapping genes between ingredients and AMI were identified using Venn diagram. Then, the interaction network between ingredients and overlapping genes was constructed, visualized, and analyzed by Cytoscape software. Protein-protein interaction (PPI) was analyzed by String database. Finally, Gene Ontology (GO) and Kyoto Encyclopedia of Genes and Genomes (KEGG) pathway enrichment analysis of overlapping genes were carried out by metascape platform.

Results: A total of 111 active ingredients, 184 ingredient-related genes, and 1020 AMI-related genes were retrieved using public databases. Eventually, 79 overlapping genes between TXL and AMI were identified. Cytoscape and PPI results suggested that the active ingredients and genes of TXL against AMI consisted of 66 active ingredients and 79 genes, among them beta-sitosterol and IL- 6 were the uppermost active ingredient and hub gene, respectively. Metascape results exhibited that the key mechanism of TXL against AMI might be reducing oxidative stress in cell membrane by inactivating pathways in cancer.

Conclusion: This network pharmacology study reveals potential mechanisms of multi-target and multicomponent TXL in the treatment of AMI, providing scientific evidence for further expounding the active ingredients and mechanisms of TXL against AMI.

\section{Introduction}

Acute myocardial infarction (AMI) is a common cardiac emergency, with the potential for subsequent morbidity and mortality.[1] Early reperfusion and restoration of the blood flow in the occluded artery remain the cornerstone for preserving the viability of the ischemic myocardium and limiting infarct size. [2] Despite the management of AMI has improved dramatically over the past three decades and continues to evolve,[3] and a decrease in AMI-related death has also been seen in some countries,[4,5] however, on the other hand, mortality seems to have plateaued or even elevated in some developing countries.[6, 7]Due to the rate of mortality and recurrent $\mathrm{MI}$ remain high after the acute phase of $\mathrm{Ml},[8]$ it is vital to improve medical care during AMI admission and integrate medical care into secondary prevention programs. As the cornerstone in anti-atherosclerotic regimen, statin has been demonstrated substantial efficacy in reducing cardiovascular events. However, the increased attention on the adverse events associated with statin such as potential harmful effects on muscle and liver has unfortunately led to statin therapy discontinuation, nonadherence to therapy or concerns about initiating statin therapy.[9] Thus, it is warranted to explore alternative anti-atherosclerotic medications with high efficacy as well as low side-effect. 
Tongxinluo (TXL), a traditional Chinese medicine (TCM) formula composed of Ginseng, Hirudo, Scorpio, Radix Paeoniae Rubra, Cicadidae, Eupolyphaga, Scolopendra, Lignum Dalbergiae Odoriferae, Santalaceae, Olibanum, Ziziphi Spinosae Semen, and Borneolum, was registered with the China State Food and Drug Administration (CFDA) in 1996. Previous studies demonstrated protective effects of TXL in a substantial number of diseases, such as pulmonary hypertension,[10] angina pectoris,[11] acute stroke,[12] atherosclerosis.[13] For the past few years, TXL has been an increasingly important strategy for treatment of atherosclerosis in China due to its good therapeutic effect and low toxic side effects. However, the chemical and pharmacological foundations of TXL in inhibiting atherosclerosis, especially AMI, was not globally evaluated with appropriate approaches. Therefore, the studies on active ingredients and mechanisms of TXL against AMI should be strengthened to provide scientific evidence to support its clinical application in treating AMI.

Because of the complex composition of TCM, conventional pharmacological approaches to experimentally identify the unique action of mechanism may not be feasible for TCM research. In order to comprehensively evaluate the active chemical ingredients and pharmacological effects of TCM, the TCM network pharmacology based on big databases has become a promising and useful tool to characterize the action mechanisms of complicated drug system in detail, ranging from the molecular level to the pathway level.[14] Network pharmacology can decipher the mechanism of drugs action with a holistic perspective, which emphasizes the paradigm shift from "one target, one drug" to "network target, multicomponent therapeutics".[15] The characteristic is paramount for TCM research, as the holistic theory has long been central to TCM treatments of various diseases.[16] Combined with pharmacology and pharmacodynamics, network pharmacology has been successfully applied to explain the mechanism of TCM at the molecular network level.[17]

In this study, we aim to utilize network pharmacology to systematically identify the active ingredients in TXL, construct a network pharmacological model of active ingredients, and analyze the potential anti-AMI mechanism of active ingredients in TXL. First, active ingredients from TXL and genes related to selected active ingredients were screened. Then, genes related to AMI were identified, and the overlapping genes between ingredients and AMI gene targets were identified. Third, interaction network between overlapping genes and related ingredients were analyzed. Fourth, protein-protein interaction (PPI) network analysis of the overlapping gene targets was conducted to investigate the interaction between overlapping gene targets. Finally, Gene Ontology (GO) and Kyoto Encyclopedia of Genes and Genomes (KEGG) pathway enrichment analysis of overlapping genes were carried out to explore the molecular mechanisms of TXL against AMI. The workflow is shown in Fig. 1.

\section{Material And Methods}

\section{Identification and Screening of Active Ingredients and Corresponding Targets in Tongxinluo}


To collect the constituent data of TXL, we primarily used the Traditional Chinese Medicine Systems Pharmacology Database[18] (TCMSP, https://tcmspw.com/tcmsp.php), a unique systems pharmacology platform of Chinese herbal medicines that captures the relationships between drugs, targets and diseases. Meanwhile, the Traditional Chinese Medicine Integrated Database[19] (TCMID, http://www.megabionet.org/tcmid/) and the Traditional Chinese Medicine Information Database[20] (TCM-ID, http://bidd.group/TCMID/) were used as supplementary databases in case data were not available in TCMSP. The effective ingredients of TXL were mainly filtered by two criteria: oral bioavailability $(O B) \geq 30 \%$ and drug-likeness $(D L) \geq 0.18$, which are the most important indicators for evaluating the characteristics of ADME (absorption, distribution, metabolism and excretion).[21] TCM is often administered orally, and its $\mathrm{OB}$ is determined by body absorption, distribution, and liver metabolism. Therefore, the degree of $\mathrm{OB}$ largely determines the effect of the ingredient on disease. DL is used to screen out first-rank ingredients and improve candidate ingredients in the early period of drug development.

The protein targets associated with active ingredients were retrieved from the TCMSP database. Full names of the protein targets were converted into gene symbol on the basis of UniProt (https://www.uniprot.org/) for following analysis.

\section{AMI-Related Targets}

The different genes associated with AMI were gathered from DisGeNET[22] (http://www.disgenet.org/), a discovery platform contains one of the largest publicly available collections of genes and variants associated with human diseases; and GeneCards[23] (https://www.genecards.org/), an integrative database that provides comprehensive information on all annotated and predicted human genes with keywords "acute myocardial infarction". Genes met Score $>0.1$ in DisGeNET or Score $>10$ in GeneCards were selected.

The overlapping genes between active ingredients and AMI were visualized by Venn diagram, plotted using the Venny 2.1.0 (https://bioinfogp.cnb.csic.es/tools/venny/), a free online platform. The overlapping gene targets of TXL and AMI were then regarded as the core targets of TXL for AMI.

\section{Protein-Protein Interaction (PPI) Network Construction of Overlapping Genes}

To explain the interaction between overlapping gene targets, PPI coming from String[24] (https://string$\mathrm{db}$.org/cgi/input.pl) with the species limited to "Homo sapiens" was constructed. The associations in STRING include direct (physical) interactions as well as indirect (functional) interactions. The website generates a score for each protein mutual information, with low confidence defined as scores $<0.4$, medium confidence defined as scores 0.4 to 0.7 , and high confidence defined as scores $>0.7$, respectively. In our analysis, PPI with direct interactions, high confidence, and hiding disconnected nodes were reserved.

\section{Network Construction}


Network construction was performed as follows: (1) herb-ingredient-target network was built by connecting herbs, chemical ingredients and corresponding targets; (2) herb-ingredient-overlapping target network was built by connecting herbs, chemical ingredients and overlapping gene targets; (3) targetpathway network was built by connecting targets and top 20 pathways; (4) ingredient-target-pathway network was built by connecting ingredients, targets, and top 20 pathways. The network of the interactions was constructed, visualized, and analyzed through Cytoscape 3.8.0[25] (http://www.cytoscape.org/), an open-source software platform which integrates biomolecular interaction networks with different types of attribute data into a unified conceptual framework. Nodes in network indicate herbs, ingredients, gene targets, or pathways, while edges between nodes suggest interactions between herbs, ingredients, gene targets, or pathways.

The key active ingredients of TXL against AMI were selected out by setting "Degree value", which represents the edge numbers of ingredients in network. The larger the value of ingredients is, the more important they are for the therapeutic effect of TXL on AMI.

\section{Gene Ontology and Pathway Enrichment of Overlapping Genes}

To elucidate the role of overlapping gene targets in gene function and signaling pathway, Metascape[26] (https://metascape.org/), a web-based portal designed to provide a comprehensive gene list annotation and analysis resource, was applied to perform Gene Ontology (GO) and Kyoto Encyclopedia of Genes and Genomes (KEGG) pathway enrichment analysis. Enriched GO terms and pathways were defined as those with False Discovery Rate (FDR) $<0.05$. In GO enrichment analysis, the bubble chart was plotted by using the Rpackage "clusterProfiler".

\section{Results}

\section{Active Ingredients and Corresponding Gene Targets in TXL}

All chemicals that meet the screening criteria: $\mathrm{OB}>30 \%$ and $\mathrm{DL}>0.18$ were considered as candidate active ingredients. Eventually, a total of 111 active ingredients were retrieved in TCMSP, TCMID, and TCMID databases after screening ADME parameters, including 37 ingredients from Lignum Dalbergiae Odoriferae, 29 ingredients from Radix Paeoniae Rubra, 22 ingredients from Ginseng, 9 ingredients from Ziziphi Spinosae Semen, 8 ingredients from Olibanum, 3 ingredients from Borneolum, 3 ingredients from Santalaceae, 2 ingredients from Eupolyphaga, 2 ingredients from Scorpio, 1 ingredient from Scolopendra, and 1 ingredient from Hirudo, respectively. Notably, MOL000358(beta-sitosterol) was the common active ingredient among Radix Paeoniae Rubra, Ginseng, and Lignum Dalbergiae Odoriferae, MOL000359(sitosterol) was the common active ingredient between Lignum Dalbergiae Odoriferae and Radix Paeoniae Rubra; MOL000422(kaempferol) was the common active ingredient between Ginseng and Eupolyphaga; MOL000449(Stigmasterol) was the common active ingredient between Ginseng and 
Radix Paeoniae Rubra; MOL000953(cholesterol) was the common active ingredient between Scorpio and Scolopendra. The main active ingredients of TXL are shown in Table 1. 
Table 1

Basic information of active ingredients of TXL

\begin{tabular}{|c|c|c|c|c|}
\hline Herb & Mol ID & Molecule Name & $\mathrm{OB}(\%)$ & DL \\
\hline \multirow[t]{22}{*}{ Ginseng } & MOL002879 & Diop & 43.59 & 0.39 \\
\hline & MOL000449 & Stigmasterol & 43.83 & 0.76 \\
\hline & MOL000358 & beta-sitosterol & 36.91 & 0.75 \\
\hline & MOL003648 & Inermin & 65.83 & 0.54 \\
\hline & MOL000422 & kaempferol & 41.88 & 0.24 \\
\hline & MOL004492 & Chrysanthemaxanthin & 38.72 & 0.58 \\
\hline & MOL005308 & Aposiopolamine & 66.65 & 0.22 \\
\hline & MOL005314 & Celabenzine & 101.88 & 0.49 \\
\hline & MOL005317 & Deoxyharringtonine & 39.27 & 0.81 \\
\hline & MOL005318 & Dianthramine & 40.45 & 0.2 \\
\hline & MOL005320 & arachidonate & 45.57 & 0.2 \\
\hline & MOL005321 & Frutinone $\mathrm{A}$ & 65.9 & 0.34 \\
\hline & MOL005344 & ginsenoside rh2 & 36.32 & 0.56 \\
\hline & MOL005348 & Ginsenoside-Rh4_qt & 31.11 & 0.78 \\
\hline & MOL005356 & Girinimbin & 61.22 & 0.31 \\
\hline & MOL005357 & Gomisin B & 31.99 & 0.83 \\
\hline & MOL005360 & malkangunin & 57.71 & 0.63 \\
\hline & MOL005376 & Panaxadiol & 33.09 & 0.79 \\
\hline & MOL005384 & suchilactone & 57.52 & 0.56 \\
\hline & MOL005399 & alexandrin_qt & 36.91 & 0.75 \\
\hline & MOL005401 & ginsenoside Rg5_qt & 39.56 & 0.79 \\
\hline & MOL000787 & Fumarine & 59.26 & 0.83 \\
\hline Hirudo & MOL001406 & crocetin & 35.3 & 0.26 \\
\hline \multirow[t]{2}{*}{ Scorpio } & MOL011455 & 20-hexadecanoylingenol & 32.7 & 0.65 \\
\hline & MOL000953 & cholesterol & 37.87 & 0.68 \\
\hline $\begin{array}{l}\text { Radix Paeoniae } \\
\text { Rubra }\end{array}$ & MOL001002 & ellagic acid & 43.06 & 0.43 \\
\hline
\end{tabular}




\begin{tabular}{|c|c|c|c|c|}
\hline Herb & Mol ID & Molecule Name & $\mathrm{OB}(\%)$ & $\mathrm{DL}$ \\
\hline & MOL001918 & paeoniflorgenone & 87.59 & 0.37 \\
\hline & MOL001921 & Lactiflorin & 49.12 & 0.8 \\
\hline & MOL001924 & paeoniflorin & 53.87 & 0.79 \\
\hline & MOL001925 & paeoniflorin_qt & 68.18 & 0.4 \\
\hline & MOL002714 & baicalein & 33.52 & 0.21 \\
\hline & MOL002776 & Baicalin & 40.12 & 0.75 \\
\hline & MOL000358 & beta-sitosterol & 36.91 & 0.75 \\
\hline & MOL000359 & sitosterol & 36.91 & 0.75 \\
\hline & MOL004355 & Spinasterol & 42.98 & 0.76 \\
\hline & MOL000449 & Stigmasterol & 43.83 & 0.76 \\
\hline & MOL000492 & $(+)$-catechin & 54.83 & 0.24 \\
\hline & MOL006990 & $\begin{array}{l}\text { (1S,2S,4R)-trans-2-hydroxy-1,8-cineole-B-D- } \\
\text { glucopyranoside }\end{array}$ & 30.25 & 0.27 \\
\hline & MOL006992 & $(2 \mathrm{R}, 3 \mathrm{R})-4$-methoxyl-distylin & 59.98 & 0.3 \\
\hline & MOL006994 & $\begin{array}{l}\text { 1-o-beta-d-glucopyranosyl-8-o- } \\
\text { benzoylpaeonisuffrone_qt }\end{array}$ & 36.01 & 0.3 \\
\hline & MOL006996 & 1-o-beta-d-glucopyranosylpaeonisuffrone_qt & 65.08 & 0.35 \\
\hline & MOL006999 & stigmast-7-en-3-ol & 37.42 & 0.75 \\
\hline & MOL007003 & benzoyl paeoniflorin & 31.14 & 0.54 \\
\hline & MOL007004 & Albiflorin & 30.25 & 0.77 \\
\hline & MOL007005 & Albiflorin_qt & 48.7 & 0.33 \\
\hline & MOL007008 & 4-ethyl-paeoniflorin_qt & 56.87 & 0.44 \\
\hline & MOL007012 & 4-o-methyl-paeoniflorin_qt & 56.7 & 0.43 \\
\hline & MOL007014 & 8-debenzoylpaeonidanin & 31.74 & 0.45 \\
\hline & MOL007016 & Paeoniflorigenone & 65.33 & 0.37 \\
\hline & MOL007018 & 9-ethyl-neo-paeoniaflorin A_qt & 64.42 & 0.3 \\
\hline & MOL007022 & evofolinB & 64.74 & 0.22 \\
\hline & MOL007025 & isobenzoylpaeoniflorin & 31.14 & 0.54 \\
\hline & MOL002883 & Ethyl oleate (NF) & 32.4 & 0.19 \\
\hline
\end{tabular}




\begin{tabular}{|c|c|c|c|c|}
\hline Herb & Mol ID & Molecule Name & $\mathrm{OB}(\%)$ & DL \\
\hline & MOL005043 & campest-5-en-3beta-ol & 37.58 & 0.71 \\
\hline \multirow[t]{2}{*}{ Eupolyphaga } & MOL000422 & kaempferol & 41.88 & 0.24 \\
\hline & MOL000098 & quercetin & 46.43 & 0.28 \\
\hline Scolopendra & MOL000953 & cholesterol & 37.87 & 0.68 \\
\hline \multirow{20}{*}{$\begin{array}{l}\text { Lignum } \\
\text { Dalbergiae } \\
\text { Odoriferae }\end{array}$} & MOL001040 & $\begin{array}{l}(2 \mathrm{R})-5,7-\text { dihydroxy-2-(4- } \\
\text { hydroxyphenyl)chroman-4-one }\end{array}$ & 42.36 & 0.21 \\
\hline & MOL001792 & DFV & 32.76 & 0.18 \\
\hline & MOL000228 & $\begin{array}{l}\text { (2R)-7-hydroxy-5-methoxy-2-phenylchroman-4- } \\
\text { one }\end{array}$ & 55.23 & 0.2 \\
\hline & MOL002565 & Medicarpin & 49.22 & 0.34 \\
\hline & MOL002914 & Eriodyctiol (flavanone) & 41.35 & 0.24 \\
\hline & MOL002938 & (3R)-4'-Methoxy-2',3,7-trihydroxyisoflavanone & 68.86 & 0.27 \\
\hline & MOL002939 & (3R)-5'-Methoxyvestitol & 83.06 & 0.26 \\
\hline & MOL002940 & $\begin{array}{l}\text { (3R)-3-(2,3-dihydroxy-4-methoxyphenyl)-7- } \\
\text { hydroxychroman-4-one }\end{array}$ & 52.06 & 0.27 \\
\hline & MOL002941 & $\begin{array}{l}\text { (3R)-3-(2,3-dihydroxy-4- } \\
\text { methoxyphenyl)chroman-7,8-diol }\end{array}$ & 82.35 & 0.27 \\
\hline & MOL002950 & (3R)-7,2',3'-trihydroxy-4-methoxyisoflavan & 69.65 & 0.24 \\
\hline & MOL002957 & 9-0-Methylcoumestrol & 33.73 & 0.38 \\
\hline & MOL002958 & 3'-Hydroxymelanettin & 30.69 & 0.27 \\
\hline & MOL002959 & 3'-Methoxydaidzein & 48.57 & 0.24 \\
\hline & MOL002961 & $(-)$-Vestitol & 70.29 & 0.21 \\
\hline & MOL002962 & $\begin{array}{l}\text { (3S)-7-hydroxy-3-(2,3,4- } \\
\text { trimethoxyphenyl)chroman-4-one }\end{array}$ & 48.23 & 0.33 \\
\hline & MOL002963 & 4',5',7-trimethyl-3-methoxyflavone & 40.66 & 0.25 \\
\hline & MOL002966 & Dalbergin & 78.18 & 0.2 \\
\hline & MOL002967 & $\begin{array}{l}\text { 7-hydroxy-4'-methoxy-2',5'-dioxo-4-[(3R)-2',7- } \\
\text { dihydroxy-4'-methoxyisoflavan-5'-y'] isoflavane }\end{array}$ & 34.78 & 0.7 \\
\hline & MOL002973 & Bowdichione & 55.78 & 0.28 \\
\hline & MOL002975 & butin & 69.94 & 0.21 \\
\hline
\end{tabular}




\begin{tabular}{|c|c|c|c|c|}
\hline Herb & Mol ID & Molecule Name & $\mathrm{OB}(\%)$ & DL \\
\hline & MOL002981 & Duartin & 70.63 & 0.34 \\
\hline & MOL002982 & $\begin{array}{l}(3 R, 4 R)-3 \text { ',7-dihydroxy-2',4'-dimethoxy-4- } \\
{[(2 S)-4 \text { ',5,7-trihydroxyflavanone-6-yl]isoflavan }}\end{array}$ & 33.96 & 0.63 \\
\hline & MOL002985 & isoduartin & 74.11 & 0.34 \\
\hline & MOL002989 & 4-Hydroxyhomopterocarpin & 48.41 & 0.43 \\
\hline & MOL002990 & $\begin{array}{l}\text { (6aR,11aR)-3,9,10-trimethoxy-6a,11a-dihydro- } \\
\text { 6H-benzofurano[3,2-c]chromen-4-ol }\end{array}$ & 66.86 & 0.53 \\
\hline & MOL002991 & $\begin{array}{l}\text { (6aR,11aR)-3,9-dimethoxy-6a,11a-dihydro-6H- } \\
\text { benzofurano[3,2-c]chromene-4,10-diol }\end{array}$ & 38.96 & 0.48 \\
\hline & MOL002996 & odoricarpin & 55.02 & 0.53 \\
\hline & MOL002997 & $\begin{array}{l}\text { 3-(2-hydroxy-3,4-dimethoxyphenyl)-2H- } \\
\text { chromen-7-ol }\end{array}$ & 86.18 & 0.27 \\
\hline & MOL002999 & Sativanone & 85.63 & 0.27 \\
\hline & MOL003000 & Stevein & 36.54 & 0.24 \\
\hline & MOL003001 & Vestitone & 52.83 & 0.24 \\
\hline & MOL003002 & violanone & 80.24 & 0.3 \\
\hline & MOL003003 & Xenognosin B & 72.71 & 0.24 \\
\hline & MOL000358 & beta-sitosterol & 36.91 & 0.75 \\
\hline & MOL000359 & sitosterol & 36.91 & 0.75 \\
\hline & MOL000380 & $\begin{array}{l}\text { (6aR,11aR)-9,10-dimethoxy-6a,11a-dihydro-6H- } \\
\text { benzofurano[3,2-c]chromen-3-ol }\end{array}$ & 64.26 & 0.42 \\
\hline & MOL000392 & formononetin & 69.67 & 0.21 \\
\hline Santalaceae & MOL000354 & isorhamnetin & 49.6 & 0.31 \\
\hline & MOL000006 & luteolin & 36.16 & 0.25 \\
\hline & MOL002322 & isovitexin & 31.29 & 0.72 \\
\hline Olibanum & MOL001215 & tirucallol & 42.12 & 0.75 \\
\hline & MOL001241 & O-acetyl-a-boswellic acid & 42.73 & 0.7 \\
\hline & MOL001243 & 3alpha-Hydroxy-olean-12-en-24-oic-acid & 39.32 & 0.75 \\
\hline & MOL001255 & Boswellic acid & 39.55 & 0.75 \\
\hline & MOL001263 & 3-oxo-tirucallic,acid & 42.86 & 0.81 \\
\hline
\end{tabular}




\begin{tabular}{|cllcl|}
\hline Herb & Mol ID & Molecule Name & OB (\%) & DL \\
\hline & MOL001265 & acetyl-alpha-boswellic,acid & 42.73 & 0.7 \\
& MOL001272 & incensole & 45.59 & 0.22 \\
& MOL001295 & phyllocladene & 33.4 & 0.27 \\
\hline $\begin{array}{c}\text { Ziziphi Spinosae } \\
\text { Semen }\end{array}$ & MOL001521 & ceanothic acid & 33.41 & 0.77 \\
\hline & MOL001522 & (S)-Coclaurine & 42.35 & 0.24 \\
\hline MOL001525 & Daucosterol & 36.91 & 0.75 \\
\hline MOL001527 & jujuboside A_qt & 34.96 & 0.62 \\
\hline MOL001532 & phytosterol & 36.91 & 0.75 \\
\hline MOL001539 & sanjoinenine & 67.28 & 0.79 \\
\hline MOL001542 & swertisin & 31.83 & 0.75 \\
\hline MOL001546 & zizyphusine & 41.53 & 0.55 \\
\hline MOL000211 & Mairin & 55.38 & 0.78 \\
\hline MOL006861 & asiatic acid & 41.38 & 0.71 \\
\hline MOL006862 & bronyl acetate & 59.3 & 0.51 \\
\hline MOL006865 & dipterocarpol & 41.71 & 0.76 \\
\hline Bicadidae & & & \\
\hline
\end{tabular}

To further study the potential mechanism of anti-AMI, it is of paramount importance to understand the gene targets on which these ingredients act. According to the target screening of the ingredients based on TCMSP, we found that there were 184 protein targets among 10 Chinese herbs in TXL. There were 109 targets in Ginseng, 88 targets in Radix Paeoniae Rubra, 79 targets in Santalaceae, 78 targets in Lignum Dalbergiae Odoriferae, 29 targets in Ziziphi Spinosae Semen, 15 targets in Hirudo, 14 targets in Olibanum, 11 targets in Eupolyphaga, 4 targets in Scorpio, and 4 targets in Scolopendra, respectively. The targets of Borneolum and the herb Cicadidae were not found in TCMSP or alternative databases. The protein targets were converted into gene targets by UniProt. The analysis of herb-ingredient-target network relationship among 11 Chinese herbs, 111 ingredients, and 184 ingredient-related targets was shown in Fig. 2, which revealed that the interaction contained 306 nodes and 1234 edges.

\section{Identification of AMI-Related Genes}

After administration of search queries in GeneCards and DisGeNET databases, a total of 1020 AMIrelevant genes were obtained. Furthermore, intersection between ingredient-related and AMI-relevant gene 
targets were performed by Venn diagram. Eventually, a total of 79 overlapping genes were obtained. The Venn diagram of overlapping genes was displayed in Fig. 3.

\section{Key Active Ingredients of TXL Against AMI}

The interactions between 79 overlapping genes and corresponding ingredients and herbs were visualized by network in Fig. 4, which includes 155 nodes and 627 edges. The results suggested that the therapeutic effect of TXL on AMI was directly related to 10 herbs, 66 active ingredients, and 79 genes. Lignum Dalbergiae Odoriferae had 29 active ingredients, which was the largest number among the 10 herbs. Based on the degree value of each ingredient, it was very easy to distinguish the contribution difference of 66 active ingredients to TXL against AMI. Beta-sitosterol (Table 2), which connected to 53 genes, was considered as the uppermost active ingredient of TXL against AMI. 
Table 2

A list of the main ingredients linking to overlapping gene targets

\begin{tabular}{|c|c|c|c|c|}
\hline No. & Mol ID & Ingredient & $\begin{array}{l}\text { Gene } \\
\text { Number }\end{array}$ & Herb \\
\hline 1 & MOL000358 & beta-sitosterol & 53 & $\begin{array}{l}\text { Radix Paeoniae } \\
\text { Rubra }\end{array}$ \\
\hline 2 & MOL000422 & Diop & 38 & Ginseng \\
\hline 3 & MOL000006 & luteolin & 30 & Santalaceae \\
\hline 4 & MOL000449 & Stigmasterol & 27 & Ginseng \\
\hline 5 & MOL000392 & formononetin & 20 & $\begin{array}{l}\text { Lignum } \\
\text { Dalbergiae } \\
\text { Odoriferae }\end{array}$ \\
\hline 6 & MOL002961 & (-)-Vestitol & 19 & $\begin{array}{l}\text { Lignum } \\
\text { Dalbergiae } \\
\text { Odoriferae }\end{array}$ \\
\hline 6 & MOL003003 & Xenognosin B & 19 & $\begin{array}{l}\text { Lignum } \\
\text { Dalbergiae } \\
\text { Odoriferae }\end{array}$ \\
\hline 8 & MOL002714 & baicalein & 18 & $\begin{array}{l}\text { Radix Paeoniae } \\
\text { Rubra }\end{array}$ \\
\hline 9 & MOL000354 & isorhamnetin & 17 & Santalaceae \\
\hline 10 & MOL002985 & isoduartin & 16 & $\begin{array}{l}\text { Lignum } \\
\text { Dalbergiae } \\
\text { Odoriferae }\end{array}$ \\
\hline 11 & MOL002981 & Duartin & 15 & $\begin{array}{l}\text { Lignum } \\
\text { Dalbergiae } \\
\text { Odoriferae }\end{array}$ \\
\hline 12 & MOL002565 & Medicarpin & 14 & $\begin{array}{l}\text { Lignum } \\
\text { Dalbergiae } \\
\text { Odoriferae }\end{array}$ \\
\hline 12 & MOL002963 & 4',5',7-trimethyl-3-methoxyflavone & 14 & $\begin{array}{l}\text { Lignum } \\
\text { Dalbergiae } \\
\text { Odoriferae }\end{array}$ \\
\hline 14 & MOL000787 & Fumarine & 12 & Ginseng \\
\hline 14 & MOL002950 & (3R)-7,2',3'-trihydroxy-4-methoxyisoflavan & 12 & $\begin{array}{l}\text { Lignum } \\
\text { Dalbergiae } \\
\text { Odoriferae }\end{array}$ \\
\hline 14 & MOL002962 & $\begin{array}{l}\text { (3S)-7-hydroxy-3-(2,3,4- } \\
\text { trimethoxyphenyl)chroman-4-one }\end{array}$ & 12 & $\begin{array}{l}\text { Lignum } \\
\text { Dalbergiae } \\
\text { Odoriferae }\end{array}$ \\
\hline
\end{tabular}




\begin{tabular}{|c|c|c|c|c|}
\hline No. & Mol ID & Ingredient & $\begin{array}{l}\text { Gene } \\
\text { Number }\end{array}$ & Herb \\
\hline 14 & MOL002999 & Sativanone & 12 & $\begin{array}{l}\text { Lignum } \\
\text { Dalbergiae } \\
\text { Odoriferae }\end{array}$ \\
\hline 14 & MOL003001 & Vestitone & 12 & $\begin{array}{l}\text { Lignum } \\
\text { Dalbergiae } \\
\text { Odoriferae }\end{array}$ \\
\hline 19 & MOL001002 & ellagic acid & 11 & $\begin{array}{l}\text { Radix Paeoniae } \\
\text { Rubra }\end{array}$ \\
\hline 19 & MOL002941 & $\begin{array}{l}\text { (3R)-3-(2,3-dihydroxy-4- } \\
\text { methoxyphenyl)chroman-7,8-diol }\end{array}$ & 11 & $\begin{array}{l}\text { Lignum } \\
\text { Dalbergiae } \\
\text { Odoriferae }\end{array}$ \\
\hline 19 & MOL002990 & $\begin{array}{l}\text { (6aR,11aR)-3,9,10-trimethoxy-6a,11a-dihydro- } \\
\text { 6H-benzofurano[3,2-c]chromen-4-ol }\end{array}$ & 11 & $\begin{array}{l}\text { Lignum } \\
\text { Dalbergiae } \\
\text { Odoriferae }\end{array}$ \\
\hline 22 & MOL005321 & Frutinone $\mathrm{A}$ & 10 & Ginseng \\
\hline 22 & MOL002940 & $\begin{array}{l}\text { (3R)-3-(2,3-dihydroxy-4-methoxyphenyl)-7- } \\
\text { hydroxychroman-4-one }\end{array}$ & 10 & $\begin{array}{l}\text { Lignum } \\
\text { Dalbergiae } \\
\text { Odoriferae }\end{array}$ \\
\hline 22 & MOL002996 & odoricarpin & 10 & $\begin{array}{l}\text { Lignum } \\
\text { Dalbergiae } \\
\text { Odoriferae }\end{array}$ \\
\hline
\end{tabular}

\section{Analysis of PPI Network}

Overlapping genes were submitted to STRING for PPI network construction, and high confidence of interaction data with a score $>0.7$ was selected (Fig. 4A). PPI was displayed by a total of 79 nodes and 416 edges with average node degree of 10.5, of which nodes represented the gene targets and the edges represented the interactions between the genes. In this network interaction (Fig. 4B), the darker the color, the stronger the gene corresponding to the node, which indicates that the gene plays a key role in the whole interaction network and is an important gene target. Figure 4B showed that $I L 6, A K T 1, T N F, J U N$, TP53, MAPK8, VEGF, MMP9, and NOS3 were centrally located in the PPI network, indicating that these genes were involved in the main pathogenesis of AMI. IL6 showed the highest degree in interaction with 36 times, followed by AKT1 (34 times), TNF (32 times), JUN (31 times), TP53 (30 times), and MAPK8 (30 times), respectively. Top 20 genes with higher interaction times were shown in Fig. 4C.

\section{GO Analysis of Overlapping Gene targets}

The top 20 significantly enriched terms in biological process (BP), cellular component (CC), and molecular function (MF) categories were selected, according to $P<0.05$. As shown in Fig. $5 \mathrm{~A}$, in the $\mathrm{BP}$ category, four terms were involved in oxidative stress or oxidative stress-related progress: response to oxidative stress, response to reactive oxygen species, cellular response to oxidative stress, and cellular 
response to reactive oxygen species. In the CC category, the gene targets were mainly classified into membrane raft, membrane microdomain, and membrane region (Fig. 5B). Simultaneously, MF terms mainly contained receptor ligand activity, signaling receptor activator activity, and endopeptidase activity (Fig. 5C).

\section{KEGG enrichment analysis}

To further clarify the relationship between overlapping gene targets and the pathways, the top 20 pathways involving 61 gene targets were screened according to the KEGG analysis with $P<0.05$ (Fig. 7A7C). The results showed that these target proteins were mainly involved in pathways in cancer, AGE-RAGE signaling pathway in diabetic complications, and Fluid shear stress and atherosclerosis, and so on. The gene targets involved in cancer pathway included $A K T 1, A R, B A X, B C L 2, C A S P 3, C A S P 7, C A S P 9, C C N D 1$, CXCL8, EGLN1, ESR1, ESR2, F2, GSK3B, GSTM1, GSTP1, HMOX1, IFNG, IGF2, IL4, IL6, JUN, MAPK1, MAPK8, MMP1, MMP2, MMP9, PIM1, PPARG, PTGS2, RELA, TGFB1, TP53, and VEGFA. Meanwhile, AKT1, BAX, BCL2, CASP3, CCND1, CXCL8, ICAM1, IL1B, IL6, JUN, MAPK1, MAPK14, MAPK8, MMP2, NOS3, PIM1, RELA, TGFB1, TNF, VCAM1, and VEGFA involved in the AGE-RAGE signaling pathway in diabetic complications. The gene targets involved in Fluid shear stress and atherosclerosis were $A K T 1, B C L 2$, GSTM1, GSTP1, HMOX1, ICAM1, IFNG, IL 1B, JUN, KDR, MAPK14, MAPK8, MMP2, MMP9, NCF1, NOS3, RELA, TNF, TP53, VCAM1, and VEGFA. Obviously, there are multiple gene targets in one pathway, and the same gene target exists in multiple pathways (Fig. 7D).

\section{Discussion}

TCM has a long history in the treatment of chronic diseases such as coronary artery disease and various complications. In the pharmacological research of active ingredients, due to the complex composition of TCM, conventional pharmacological approaches to identify the unique ingredients and mechanisms may not be feasible. However, the active ingredients and gene targets are important in uncovering the pharmacological mechanisms of TCM, which can provide a theoretical basis for drug development and design.[27] Therefore, the network pharmacology provides a unique and innovative way to study the active ingredients and understand the mechanisms of multi-ingredient-multi-target-multi-pathway mode of TCM.[28]

In this study, 111 active ingredients and 184 gene targets in TXL were determined by TCMSP database. Subsequently, 79 overlapping genes related to AMI were obtained. Herb-ingredient-overlapping target network suggested that the therapeutic effect of TXL on AMI was directly related to 66 active ingredients. Based on the degree value of each ingredient, beta-sitosterol was considered as the uppermost active ingredient of TXL against AMI. PPI analysis showed that the hub genes were IL6, AKT1, TNF, JUN, TP53, MAPK8, VEGF, MMP9, and NOS3. GO analysis results showed that the overlapping genes were mainly involved in oxidative stress process, the main cellular component was membrane, and the main molecular function was receptor ligand activity. The main pathways were pathways in cancer, AGE-RAGE signaling pathway in diabetic complications, and Fluid shear stress and atherosclerosis. 
AMI is usually initiated by myocardial ischemia due to coronary artery obstruction. In the ischemic myocardium, reactive oxygen species (ROS) are generated, which can directly injure cell membrane and induce cell death. Meanwhile, in the ischemic and surrounding myocardium, inflammatory cytokines, e.g., tumor necrosis factor (TNF)-alpha can be produced via the generation of ROS in cardiac myocytes. TNFalpha can regulate cell survival and cell death, and act as a trigger of another inflammatory reaction. Inversely, inflammatory cytokines can also stimulate ROS formation.[29] In chronic stage, ROS and inflammatory cytokines activate the matrix metalloproteinase (MMP), which elicits the degradation of collagens and may cause a slippage in myofibrillar alignment and left ventricular dilatation. It is reported that in transgenic mice with cardiac overexpression of TNF-alpha, when MMP-2 and MMP-9 expressions were attenuated by inhibition of TNF-alpha, further collagen synthesis, deposition and denaturation were prevented and left ventricular diastolic function was improved. Furthermore, a clinical study also demonstrated a positive correlation between oxidative stress and relative level of MMP-2 and MMP-9 in patients with coronary artery disease.[30]

In our analysis, beta-sitosterol, the uppermost active ingredient of TXL against AMI, is a natural ingredient widely found in many vegetable oils, nuts and plant medicines, and resembles cholesterol structurally, which is considered as a therapeutic agent to reduce serum cholesterol levels and suppress intestinal cholesterol absorption.[31] Meanwhile, several studies also reported that beta-sitosterol functioned as important molecules in stabilizing the phospholipid bilayers of cell membranes and had the potential to suppress obesity-related chronic inflammations, revert immune abnormalities, and regulate the production of nitric oxide.[32] [33] Beta-sitosterol was effective in cardiovascular protection by enhancing cellular glutathione redox cycling, which led to reduced oxidant injury in rat cardiomyocytes.[34] Meanwhile, beta-sitosterol isolated from various plants can modulate antioxidant enzyme levels in pathogenesis and decrease free radical generation and act as scavengers of free radicals in vitro.[35] In the recent experiment conducted by Lin et al,[36] the protective effects of beta-sitosterol on myocardial ischemia/reperfusion (I/R) injury were confirmed in the in vivo animal model. The experiment suggested that I/R injury suppressed cell viability and induced cell apoptosis and ROS production, yet beta-sitosterol treatment concentration dependently increased the cell viability, reduced cell apoptotic rates and ROS production of I/R-stimulated H9c2 cells. Moreover, increased infarcted area and cell apoptosis in the heart tissues were also observed in the I/R mouse model, whereas beta-sitosterol treatment could alleviate infarction and cell apoptosis. Therefore, these results above implied that beta-sitosterol was effective in exerting protective actions against oxidative stress and myocardial I/R injury.

Interleukin (IL)-6 is a cytokine with both proinflammatory and anti-inflammatory effects on many cell types, affecting B-cell immunoglobulin production, T-cell cytotoxic activity, platelet production and reactivity, and endothelial function. [37] Meta-analysis performed by the Emerging Risk Factors Collaboration demonstrated that for each SD increase in log IL-6, there was a $25 \%$ increase in risk of future vascular events.[38] Moreover, in a randomized trial including 3,489 patients, circulating IL-6 was a strong independent marker of increased risk for mortality in patients with unstable coronary artery disease. TNF is one of the most important cytokines produced by macrophages and released very rapidly after all types of injuries and stimuli, which plays a very important role in host defense. However, 
prolonged TNF production is also associated with pathology.[39] Therefore, removal of a upregulated cytokine can make a clinical difference. A retrospective cohort study including 8,845 patients suggested that patients treated with TNF inhibitors had approximately half the risk of developing MI (hazard ratio [HR], 0.50; 95\% Cl, 0.32-0.81) compared with psoriasis patients treated with topical agents.[40] Another protein, MMP-9 is a collagenase, which upregulated in the diabetic heart, and ablation of MMP-9 decreased infarct size in the non-diabetic MI heart, which provided a novel intracellular role of MMP-9 in mediating cell death via apoptosis and pyroptosis.[41] Consistently, the results based on mouse model fed with high fat diet suggested that TXL treatment could lower the expressions of inflammatory cytokines including IL-6, TNF-alpha and MMP-2 in a dose-dependent manner when compared with the control group.[13] AKT1 is the predominant isoform in vascular endothelial cells and plays a crucial role in physiological and pathological angiogenesis.[42] Many of the angiogenic functions attributed to vascular endothelial growth factor (VEGF) are mediated by intracellular activation of the phosphoinositide 3-kinase-Akt signaling pathway. Similarly, VEGF is important in vasculogenesis, which defined as the formation of blood vessels from de novo generation of endothelial cells and angiogenesis. Again, the effect of TXL on VEGF had been explained by previous research, which indicated that the VEGF expression in TXL treated bone marrow mesenchymal stem cells was increased compared to the control group.[43]

Most importantly, activation of endothelial nitric oxide synthase (eNOS) in cardiac microvascular endothelial cells, whose gene name is NOS3, plays a critical role in the protection against myocardial I/R injury. In our recent experiment where ex vivo, in vivo, and in vitro settings of I/R were used, we identified the signals produced by cardiomyocytes that can regulate cardiac microvascular endothelial cells biology during myocardial I/R injury. We found that cardiac microvascular endothelial cells-derived eNOS activity was required for the cardioprotection of TXL,[44] which again confirmed the mechanism of TXL in the treatment of AMI.

KEGG enrichment analysis suggested that the main pathway was pathways in cancer. Similar with cancer cells, ischemic myocardium are also characterized by high levels of oxidative stress.[45] At low levels, ROS increase cell proliferation and survival through the post-translational modification of kinases and phosphatases, which is required for homeostatic signaling events. At moderate levels, ROS induce the expression of stress-responsive genes, which in turn trigger the expression of proteins providing prosurvival signals, such as VEGF.[46] At high levels, however, ROS can result in damage to macromolecules, including DNA, and cause permeabilization of the mitochondria, leading to the release of cytochrome $c$ and apoptosis.[47] The abovementioned process was similar to that of I/R injury in patients with myocardial infarction.[48] Consistent with our KEGG pathway analysis, in a study investigating the anti-oxidation properties of $T X L$, the authors found that the remarkably up-regulated expression of NADPH oxidase subunits $\mathrm{p} 22^{\text {phox }}, \mathrm{p} 47^{\text {phox }}$ and inflammatory factors TNF-alpha, IL-1 $\beta$ and NF-KB induced by $\mathrm{C} 16$ could be obviously decreased following pretreatment with TXL,[49] which again highlighted the important role of TXL in the process of oxidative stress. Meanwhile, the main pathway of TXL against AMI was also involved in AGE-RAGE signaling pathway in diabetic complications, which 
indicated that TXL may be effective in decreasing diabetic complication. The Fluid shear stress and atherosclerosis pathway has been confirmed.[13]

In our China Tongxinluo Study for myocardial protection in patients with Acute Myocardial Infarction (CTS-AMI) trial,[50] we are going to recruit 3,796 eligible patients with ST-segment elevation myocardial infarction (STEMI) from 120 centers and randomize them in a 1:1 ratio to TXL or placebo groups. The primary endpoint is 30-day major adverse cardiovascular and cerebrovascular events composed of cardiac death, myocardial reinfarction, emergency coronary revascularization, and stroke. Based on the results of CTS-AMI trial, we sought to determine the clinical efficacy, safety, and mechanisms of TXL in the treatment of STEMI patients in the reperfusion era.

There are several limitations in our study. First, our results need to be further verified by experiments. However, findings from our study provided insight into the research of TXL. Meanwhile, in our CTS-AMI trial, we are going to systematically elucidate the efficacy and mechanisms of TXL in the treatment of AMI, which is helpful in explaining the role of TXL. Second, the TCMSP database had not been updated since 2014,[18] therefore, we still could not completely understand the accurate therapeutic mechanism of TXL on AMI despite the results of network pharmacology. More comprehensive and timely updated TCM databases are needed to make the results of network pharmacology analysis more reliable. A comprehensive understanding of the effect of TXL on AMI depends on the common development of multi-disciplines and further invalidation both in experimental and clinical situation.

\section{Conclusion}

In conclusion, the findings of this work suggested that the active ingredients and genes of TXL against AMI consisted of 66 active ingredients and 79 genes, beta-sitosterol and IL- 6 were the uppermost active ingredient and hub gene respectively in the course of against AMI. The key mechanism might be related to oxidative stress in the membrane. This work provides scientific evidence to support the clinical effect of TXL on AMI. However, deep analysis of anti-AMI pharmacological effects of TXL, as well as the targets and pathways acting with the active ingredients still need to be further validated.

\section{Declarations}

\section{Acknowledgments}

This work was supported by CAMS Innovation Fund for Medical Sciences (CIFMS) (2016-I2M-1-009).

\section{Disclosure}

The author reports no conflicts of interest in this work.

\section{References}


1. Anderson, J.L. and Morrow, D.A. (2017) Acute Myocardial Infarction. N Engl J Med 376 (21), 20532064.

2. Vogel, B. et al. (2019) ST-segment elevation myocardial infarction. Nat Rev Dis Primers 5 (1), 39.

3. O'Gara, P.T. et al. (2013) 2013 ACCF/AHA guideline for the management of ST-elevation myocardial infarction: a report of the American College of Cardiology Foundation/American Heart Association Task Force on Practice Guidelines. Circulation 127 (4), e362-425.

4. Yeh, R.W. et al. (2010) Population trends in the incidence and outcomes of acute myocardial infarction. N Engl J Med 362 (23), 2155-65.

5. Smolina, K. et al. (2012) Determinants of the decline in mortality from acute myocardial infarction in England between 2002 and 2010: linked national database study. Bmj 344, d8059.

6. Jernberg, T. et al. (2015) Cardiovascular risk in post-myocardial infarction patients: nationwide real world data demonstrate the importance of a long-term perspective. Eur Heart J 36 (19), 1163-70.

7. Rosselló, X. et al. (2017) Global geographical variations in ST-segment elevation myocardial infarction management and post-discharge mortality. Int J Cardiol 245, 27-34.

8. Andrés, E. et al. (2012) Long-term mortality and hospital readmission after acute myocardial infarction: an eight-year follow-up study. Rev Esp Cardiol (Engl Ed) 65 (5), 414-20.

9. Adhyaru, B.B. and Jacobson, T.A. (2018) Safety and efficacy of statin therapy. Nat Rev Cardiol 15 (12), 757-769.

10. Wang, Y. et al. (2016) Effect of Tongxinluo on pulmonary hypertension and pulmonary vascular remodeling in rats exposed to a low pressure hypoxic environment. J Ethnopharmacol 194, 668-673.

11. Jia, Y. and Leung, S.W. (2015) Comparative Efficacy of Tongxinluo Capsule and Beta-Blockers in Treating Angina Pectoris: Meta-Analysis of Randomized Controlled Trials. J Altern Complement Med 21 (11), 686-99.

12. Zhuo, Q. et al. (2008) Tongxinluo capsule for acute stroke. Cochrane Database Syst Rev (4), Cd004584.

13. Ma, J. et al. (2019) Tongxinluo may stabilize atherosclerotic plaque via multiple mechanisms scanning by genechip. Biomed Pharmacother 113, 108767.

14. Chen, Y. et al. (2016) Eyes on systems pharmacology. Pharmacol Res 114, 39-41.

15. Hopkins, A.L. (2008) Network pharmacology: the next paradigm in drug discovery. Nat Chem Biol 4 (11), 682-90.

16. Li, S. et al. (2014) Network pharmacology in traditional chinese medicine. Evid Based Complement Alternat Med 2014, 138460.

17. He, D. et al. (2019) A Network Pharmacology-Based Strategy For Predicting Active Ingredients And Potential Targets Of LiuWei DiHuang Pill In Treating Type 2 Diabetes Mellitus. Drug Des Devel Ther 13, 3989-4005.

18. Ru, J. et al. (2014) TCMSP: a database of systems pharmacology for drug discovery from herbal medicines. J Cheminform 6, 13. 
19. Xue, R. et al. (2013) TCMID: Traditional Chinese Medicine integrative database for herb molecular mechanism analysis. Nucleic Acids Res 41 (Database issue), D1089-95.

20. Chen, X. et al. (2006) Database of traditional Chinese medicine and its application to studies of mechanism and to prescription validation. Br J Pharmacol 149 (8), 1092-103.

21. Ning, K. et al. (2017) Computational Molecular Networks and Network Pharmacology. Biomed Res Int $2017,7573904$.

22. Piñero, J. et al. (2020) The DisGeNET knowledge platform for disease genomics: 2019 update. Nucleic Acids Res 48 (D1), D845-d855.

23. Safran, M. et al. (2010) GeneCards Version 3: the human gene integrator. Database (Oxford) 2010, baq020.

24. Szklarczyk, D. et al. (2017) The STRING database in 2017: quality-controlled protein-protein association networks, made broadly accessible. Nucleic Acids Res 45 (D1), D362-d368.

25. Shannon, P. et al. (2003) Cytoscape: a software environment for integrated models of biomolecular interaction networks. Genome Res 13 (11), 2498-504.

26. Zhou, Y. et al. (2019) Metascape provides a biologist-oriented resource for the analysis of systemslevel datasets. Nat Commun 10 (1), 1523.

27. Boezio, B. et al. (2017) Network-based Approaches in Pharmacology. Mol Inform 36 (10).

28. Ge, Q. et al. (2018) Analysis of mulberry leaf components in the treatment of diabetes using network pharmacology. Eur J Pharmacol 833, 50-62.

29. Nakamura, K. et al. (1998) Inhibitory effects of antioxidants on neonatal rat cardiac myocyte hypertrophy induced by tumor necrosis factor-alpha and angiotensin II. Circulation 98 (8), 794-9.

30. Kameda, K. et al. (2003) Correlation of oxidative stress with activity of matrix metalloproteinase in patients with coronary artery disease. Possible role for left ventricular remodelling. Eur Heart J 24 (24), 2180-5.

31. Matsuoka, K. et al. (2008) Study of thermodynamic parameters for solubilization of plant sterol and stanol in bile salt micelles. Chem Phys Lipids 154 (2), 87-93.

32. Bouic, P.J. (2002) Sterols and sterolins: new drugs for the immune system? Drug Discov Today 7 (14), 775-8.

33. AbuMweis, S.S. et al. (2014) Implementing phytosterols into medical practice as a cholesterollowering strategy: overview of efficacy, effectiveness, and safety. Can J Cardiol 30 (10), 1225-32.

34. Wong, H.S. et al. (2014) $\beta$-Sitosterol enhances cellular glutathione redox cycling by reactive oxygen species generated from mitochondrial respiration: protection against oxidant injury in $\mathrm{H} 9 \mathrm{c} 2 \mathrm{cells}$ and rat hearts. Phytother Res 28 (7), 999-1006.

35. Moreno, J.J. (2003) Effect of olive oil minor components on oxidative stress and arachidonic acid mobilization and metabolism by macrophages RAW 264.7. Free Radic Biol Med 35 (9), 1073-81.

36. Lin, F. et al. (2020) ß-Sitosterol Protects against Myocardial Ischemia/Reperfusion Injury via Targeting PPARy/NF-kB Signalling. Evid Based Complement Alternat Med 2020, 2679409. 
37. Hunter, C.A. and Jones, S.A. (2015) IL-6 as a keystone cytokine in health and disease. Nat Immunol 16 (5), 448-57.

38. Kaptoge, S. et al. (2014) Inflammatory cytokines and risk of coronary heart disease: new prospective study and updated meta-analysis. Eur Heart J 35 (9), 578-89.

39. Udalova, I. et al. (2016) Anti-TNF Therapy. Microbiol Spectr 4 (4).

40. Armstrong, A.W. (2013) Do TNF inhibitors reduce the risk of myocardial infarction in psoriasis patients? Jama 309 (19), 2043-4.

41. Yadav, S.K. et al. (2020) MMP9 mediates acute hyperglycemia-induced human cardiac stem cell death by upregulating apoptosis and pyroptosis in vitro. Cell Death Dis 11 (3), 186.

42. Chen, J. et al. (2005) Akt1 regulates pathological angiogenesis, vascular maturation and permeability in vivo. Nat Med 11 (11), 1188-96.

43. Hu, X.Y. et al. (2011) Tongxinluo promotes mesenchymal stem cell tube formation in vitro. J Zhejiang Univ Sci B 12 (8), 644-51.

44. Chen, G. et al. (2020) Cardiomyocyte-derived small extracellular vesicles can signal eNOS activation in cardiac microvascular endothelial cells to protect against Ischemia/Reperfusion injury. Theranostics 10 (25), 11754-11774.

45. Cairns, R.A. et al. (2011) Regulation of cancer cell metabolism. Nat Rev Cancer 11 (2), 85-95.

46. Gao, P. et al. (2007) HIF-dependent antitumorigenic effect of antioxidants in vivo. Cancer Cell 12 (3), 230-8.

47. Garrido, C. et al. (2006) Mechanisms of cytochrome c release from mitochondria. Cell Death Differ $13(9), 1423-33$.

48. Cadenas, S. (2018) ROS and redox signaling in myocardial ischemia-reperfusion injury and cardioprotection. Free Radic Biol Med 117, 76-89.

49. Wu, X.L. et al. (2015) Chinese medicine Tongxinluo reduces atherosclerotic lesion by attenuating oxidative stress and inflammation in microvascular endothelial cells. Int J Clin Exp Pathol 8 (6), 6323-33.

50. Xu, Y. et al. (2020) China Tongxinluo Study for myocardial protection in patients with Acute Myocardial Infarction (CTS-AMI): Rationale and design of a randomized, double-blind, placebocontrolled, multicenter clinical trial. Am Heart J 227, 47-55.

\section{Figures}


TCMSP, TCMID, and TCM-ID databases

\section{Cytoscape}

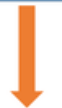

11 herbs, 111 active ingredients, and 184 corresponding gene targets herb-ingredient-target network
GeneCards and DisGeNET databases

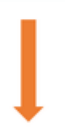

1020 gene targets on AMl

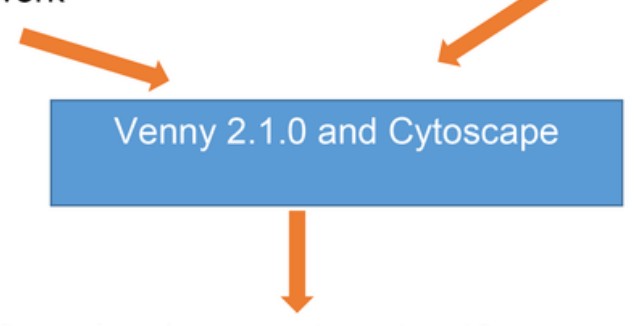

79 overlapping gene targets, 10 corresponding herbs and 66 active ingredients herb-ingredient-overlapping target network

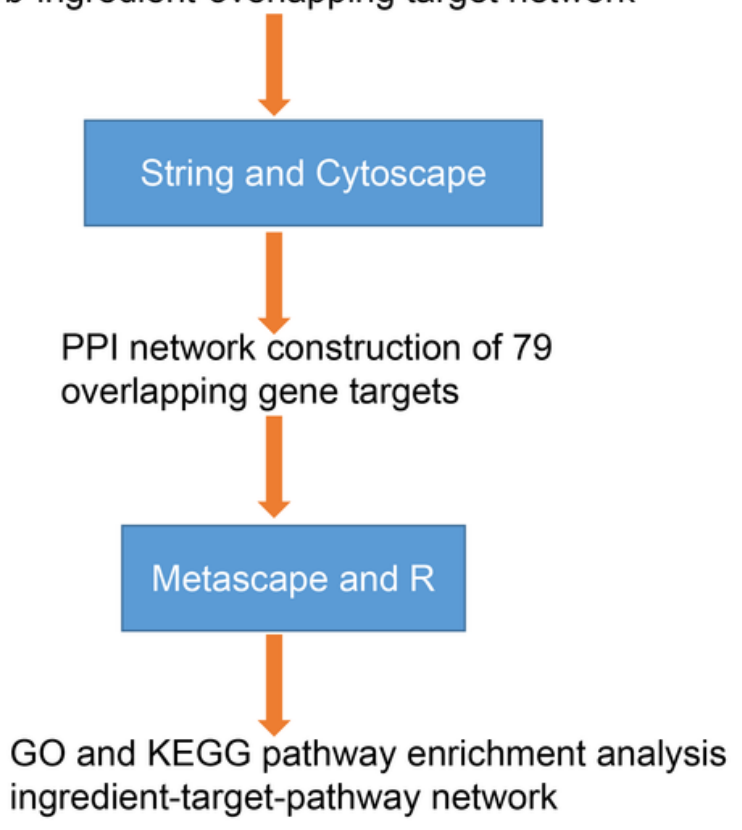

\section{Figure 1}

The flowchart of the network pharmacological analysis approach. Abbreviations: AMI, acute myocardial infarction, PPI, protein-protein interaction, GO, Gene Ontology, KEGG, Kyoto Encyclopedia of Genes and Genomes 


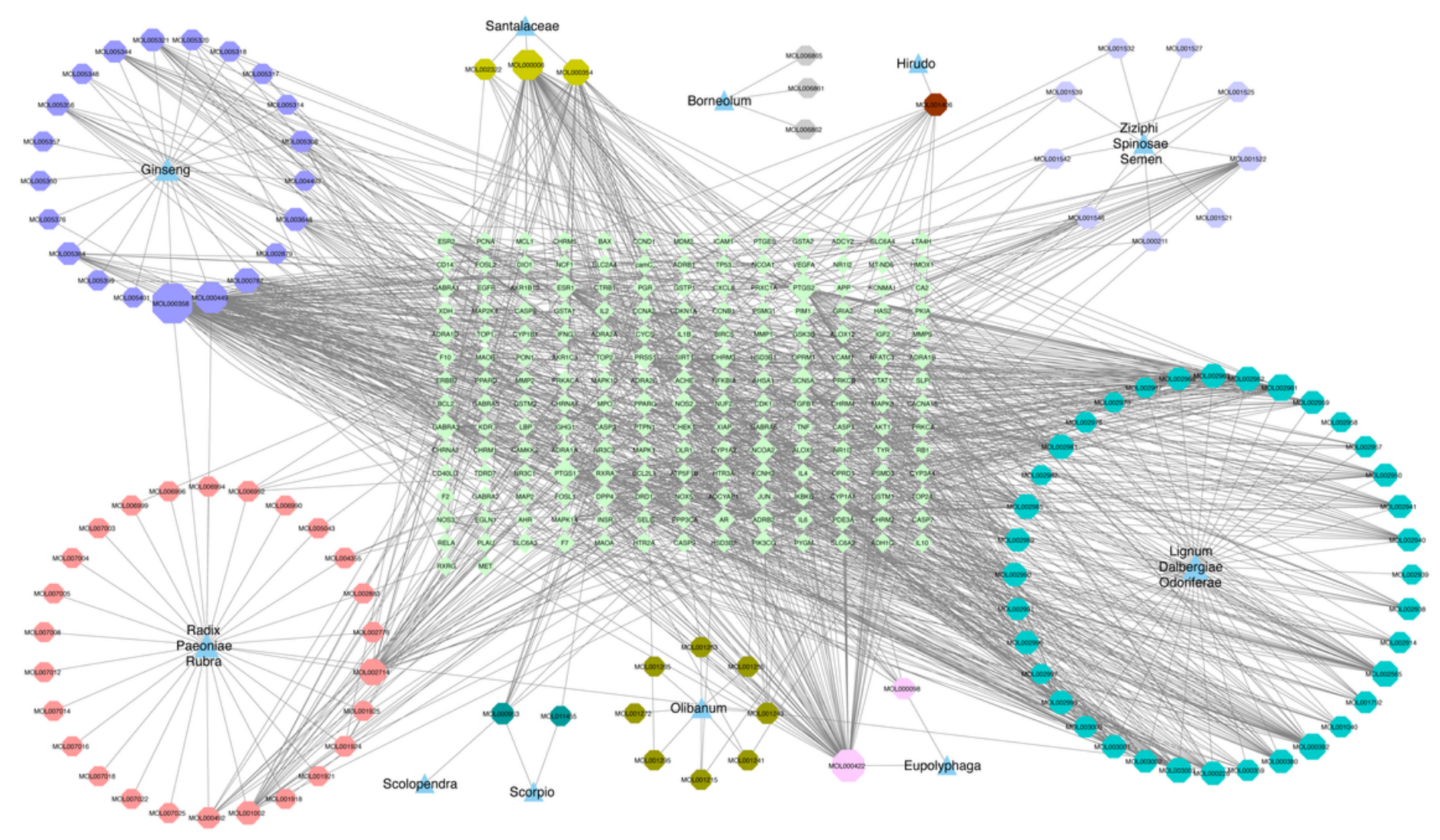

Figure 2

Herb-ingredient-target interaction network. Notes: The cyan triangles represent the 11 herbs, the octagons with different color represent the corresponding active ingredients, the aqua diamonds in the middle represent the corresponding gene targets. 


\section{Tongxinluo}

\section{Acute MI}

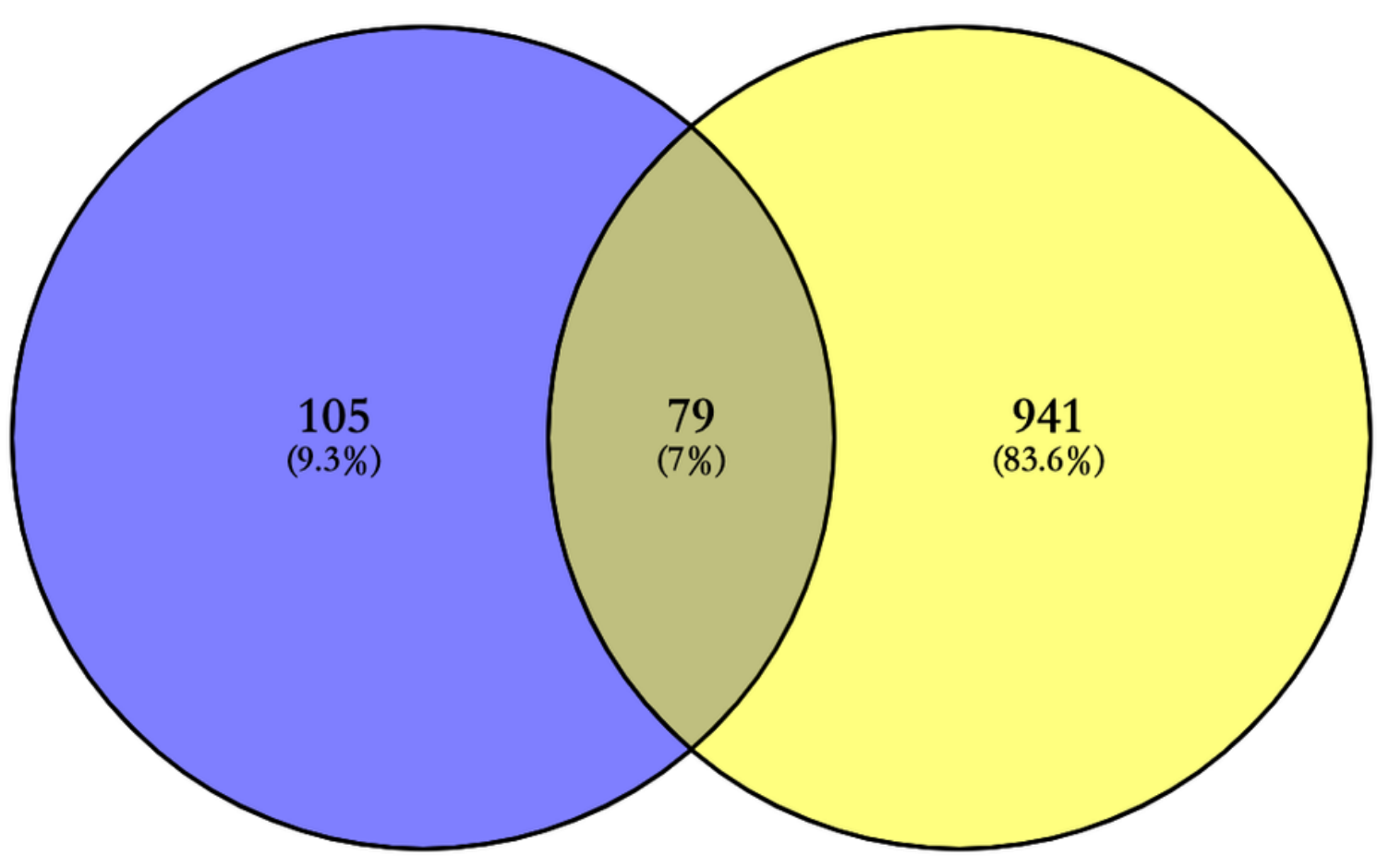

Figure 3

Venn diagram of the overlapping genes between Tongxinluo and AMI. 


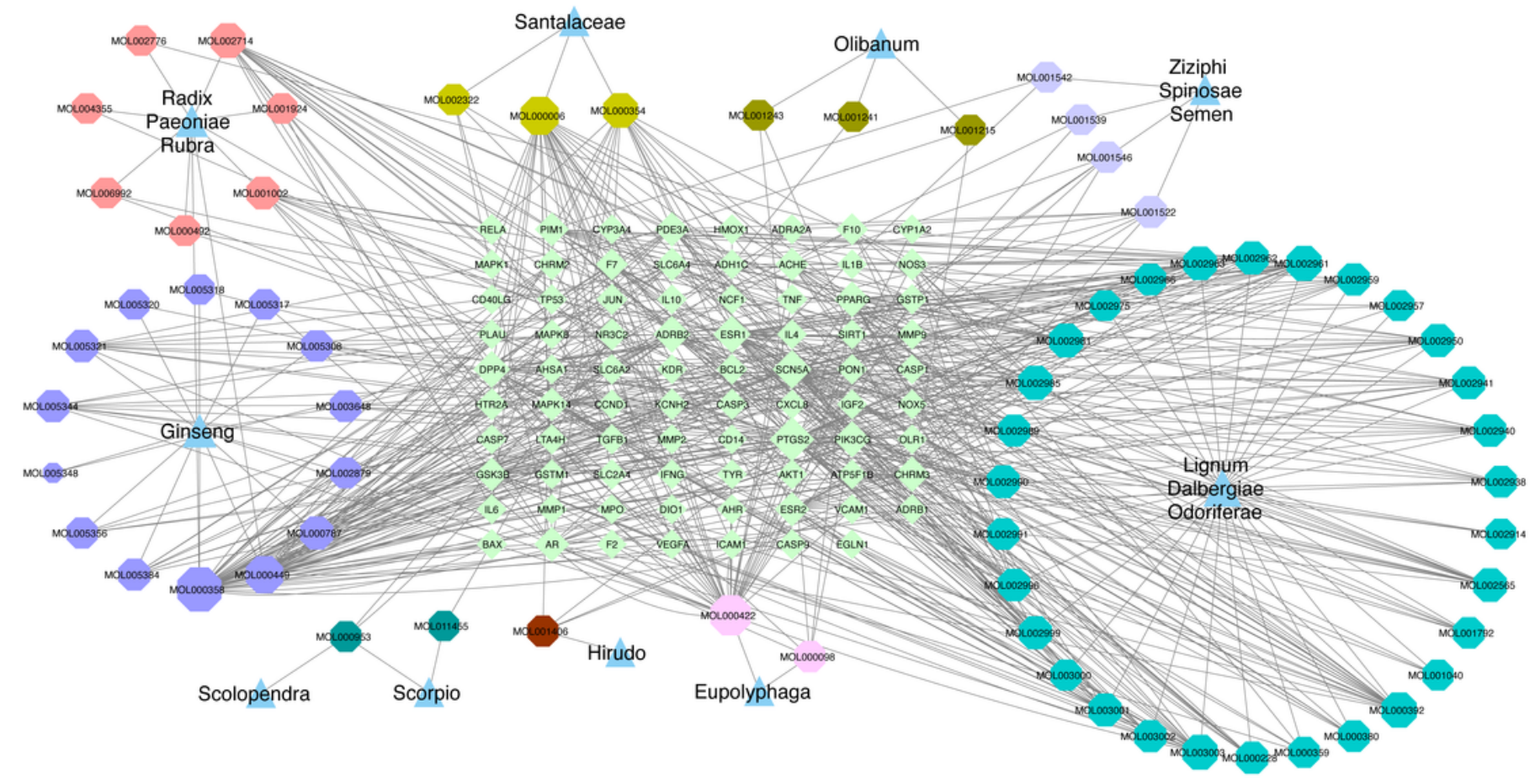

Figure 4

Herb-ingredient-target interaction network. Notes: The cyan triangles represent the 10 herbs, the octagons with different color represent the corresponding active ingredients, the aqua diamonds in the middle represent the corresponding gene targets. 


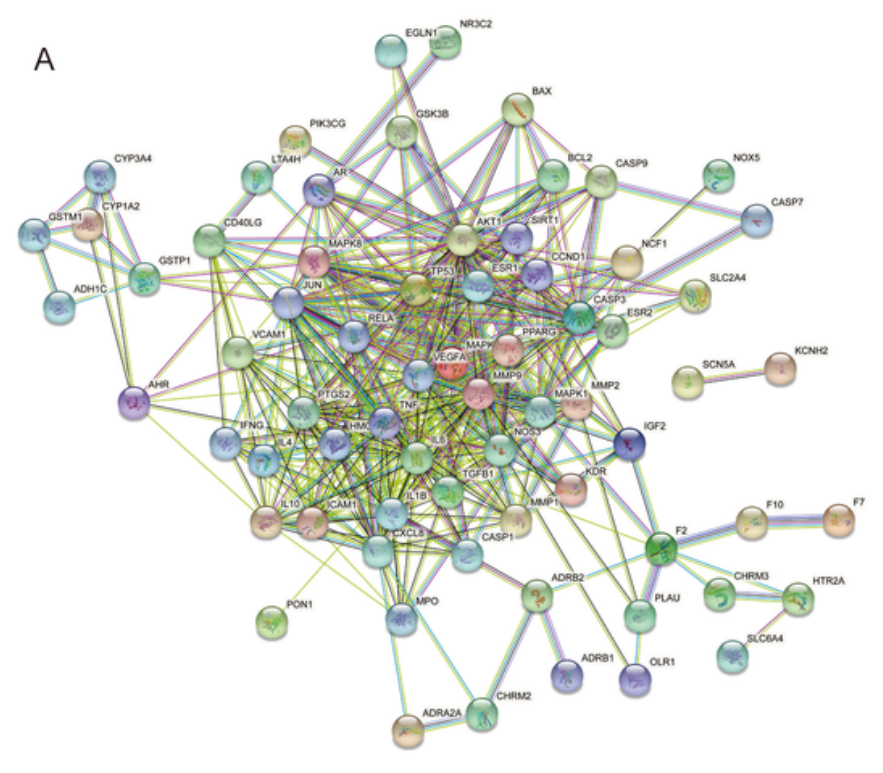

\section{B}
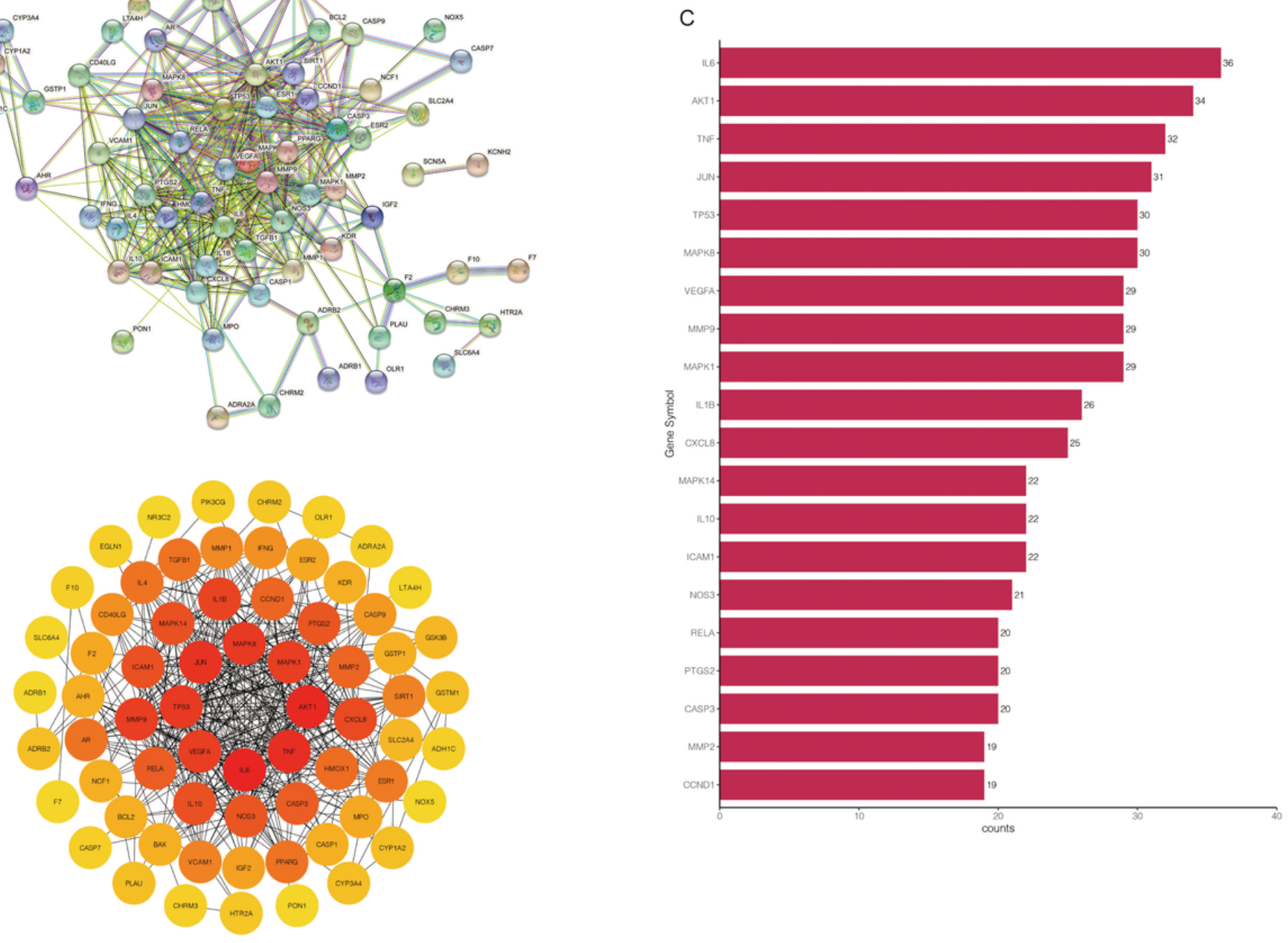

Figure 5

PPI network analysis of the overlapping gene targets. 

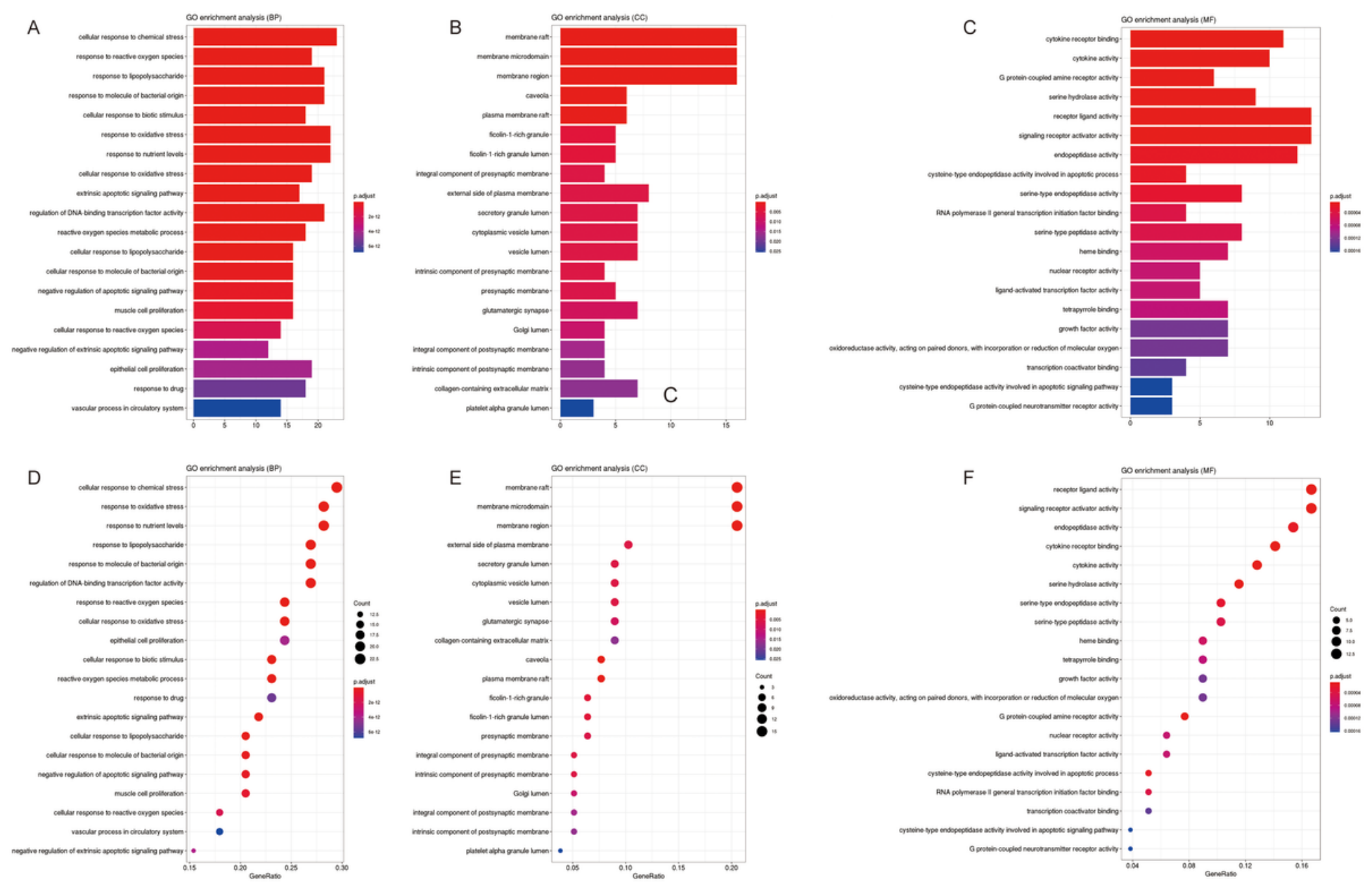

\section{Figure 6}

GO enrichment analysis of the overlapping gene targets. Notes: A, Bar graph of BP analyses. B, Bar graph of CC analyses. C, Bar graph of MF analyses. D, Dot plot of BP analyses. E, Dot plot of CC analyses. F, Dot plot of MF analyses. GO: gene ontology, BP: biological process, CC: cellular component, MF: molecular function. 
A

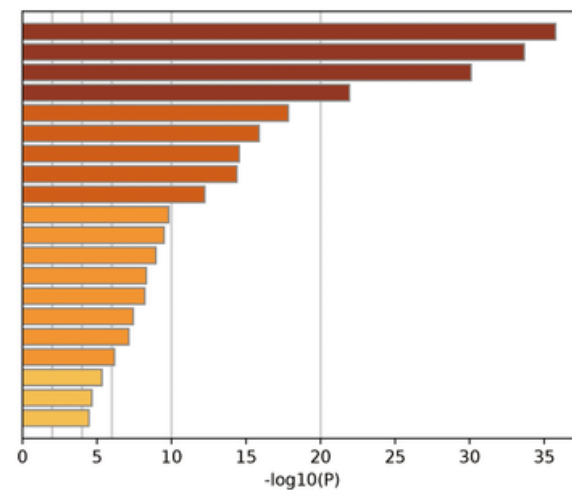

ina05200: Pathways in cance and atherosclerosis hsa5167. kaposi sarcoma-associated herpesvirus infection hsa05205: Proteoglycans in cancer ko 144 . Malaria

B signaling pathway

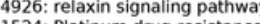

Transcriptional misregulation in cancer sa04931: insulin resistance

k004024: CAMP signaling pathway sa05204: Chemical carcinogenesis hsa04725: Cholinergic synapse ko05330: Allograft rejection hsa04211: Longevity regulating pathway ko04921: Oxytocin signaling pathway hsa04726: Serotonergic synapse 004137: Mitophagy animat
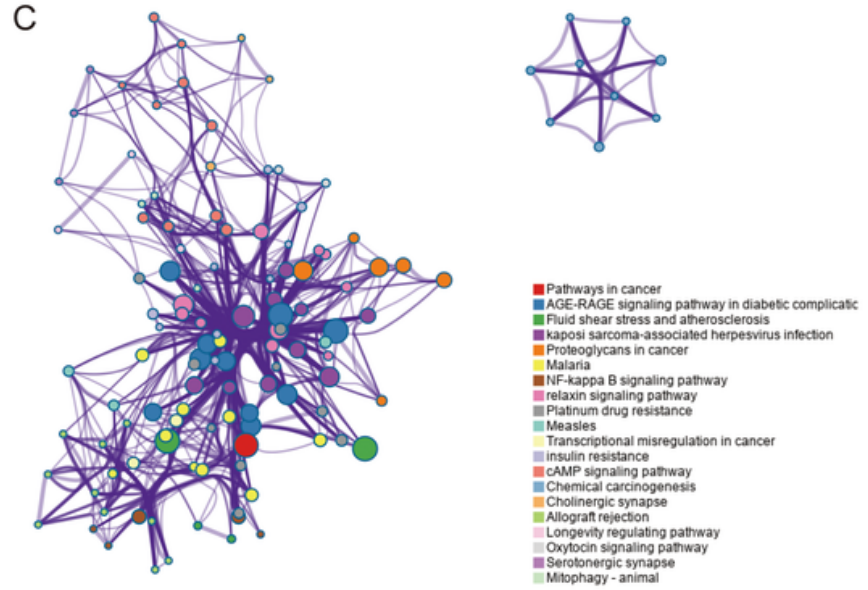

B
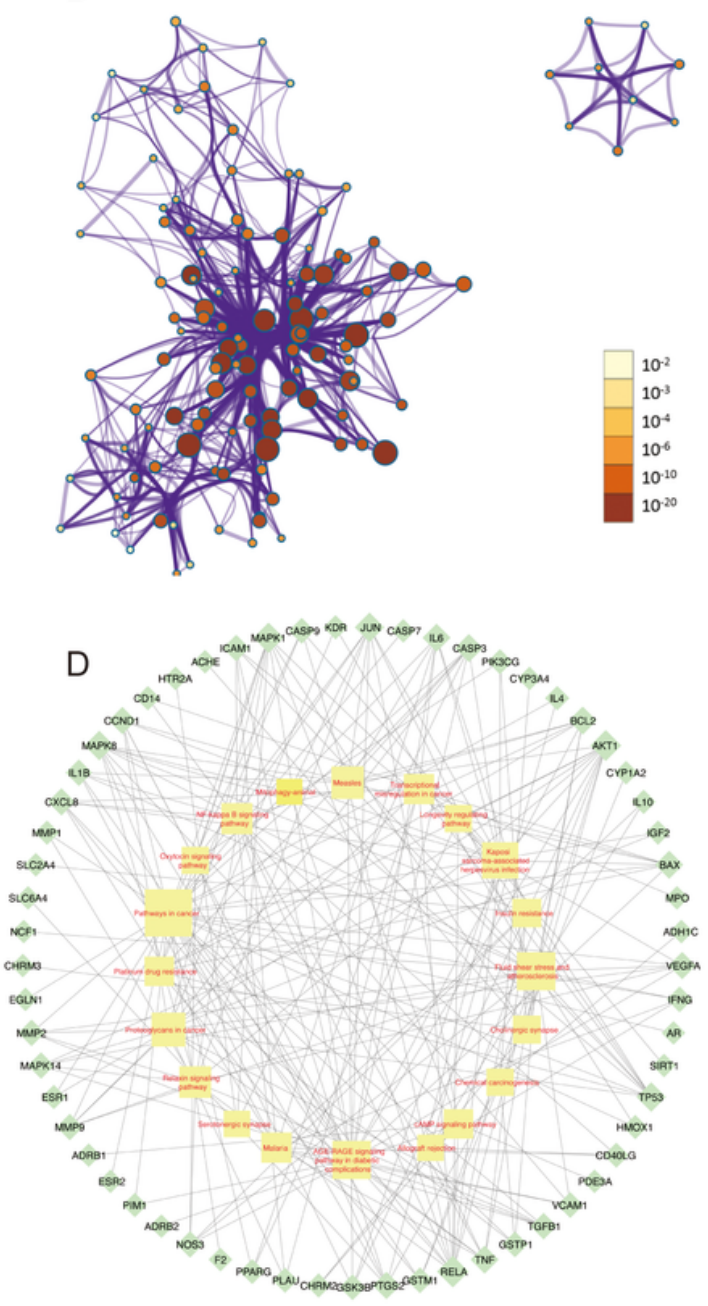

\section{Figure 7}

KEGG analysis of gene targets (A-C) and target-pathway interaction network (D). Notes: The aqua diamonds represent the gene targets, and the yellow rectangles represent the top 20 pathways. 


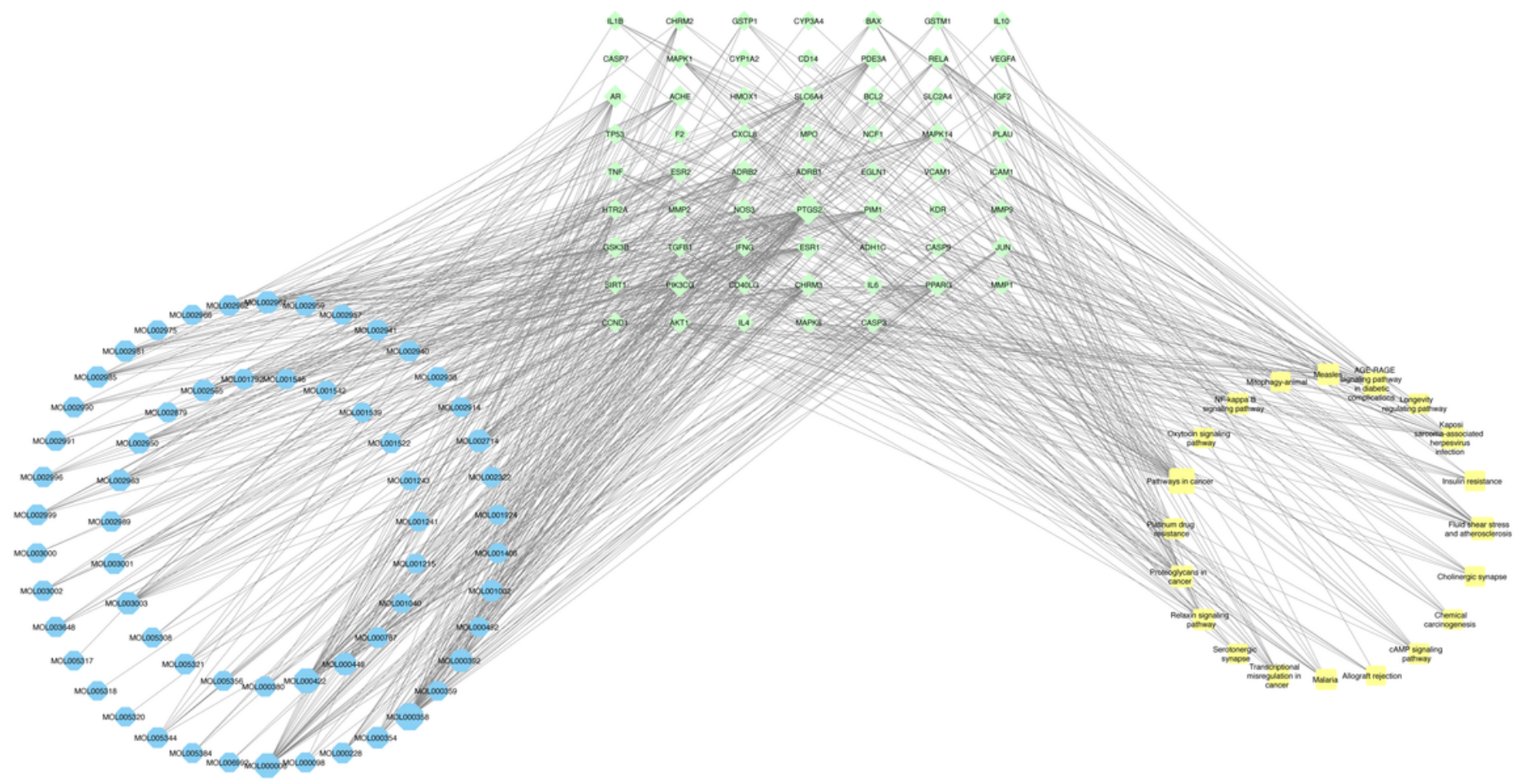

Figure 8

Ingredient-target-pathway interaction network. Notes: The blue octagons represent the active ingredients, the aqua diamonds in the middle represent the gene targets, and the yellow rectangles represent the top 20 pathways. 